\title{
Heavy metal deposition through rainfall in Chinese natural terrestrial ecosystems: Evidences from national-scale network monitoring
}

\author{
Jianxing Zhu ${ }^{\text {a, b }}$, Qiufeng Wang ${ }^{\text {a, b, }{ }^{* *}, \text { Haili Yu }}{ }^{\text {a, b }}$, Meiling Li ${ }^{\text {a }}$, Nianpeng He ${ }^{\text {a, b, * }}$ \\ ${ }^{a}$ Key Laboratory of Ecosystem Network Observation and Modeling, Institute of Geographic Sciences and Natural Resources Research, Chinese Academy of \\ Sciences, Beijing 100101, China \\ ${ }^{\mathrm{b}}$ University of Chinese Academy of Sciences, Beijing 100049, China
}

\section{H I G H L I G H T S}

- Investigating heavy metal deposition through rainfall in Chinese natural ecosystem.

- Precipitation, vehicles number, energy consumption affect heavy metal deposition.

- Wet heavy metals deposition was positive correlated with soil metals contents.

- Increasing heavy metals deposition have adverse effects on natural ecosystem.

\section{A R T I C L E I N F O}

\section{Article history:}

Received 22 January 2016

Received in revised form

8 August 2016

Accepted 22 August 2016

Available online 30 August 2016

Handling Editor: Martine Leermakers

\section{Keywords:}

Wet deposition

Heavy metal

Lead

Cadmium

Chromium

\begin{abstract}
A B S T R A C T
Industrialization and urbanization have led to increasingly serious levels of atmospheric heavy metal pollution, which is one of the main sources of heavy metals to terrestrial ecosystems. Therefore, it is essential to quantify atmospheric fluxes and explore their potential effects on natural ecosystems and human welfare. We monitored water-soluble heavy metals (lead (Pb), cadmium (Cd), and chromium (Cr)) in rainfalls on a monthly basis in 2013 and 2014, at 31 field stations located in typical natural Chinese ecosystems. The average soluble $\mathrm{Pb}, \mathrm{Cd}$, and $\mathrm{Cr}$ deposition was $1.90 \pm 1.54,0.28 \pm 0.25$, and $0.96 \pm 0.48 \mathrm{mg} \mathrm{m}^{-2} \mathrm{yr}^{-1}$, respectively, with a large variation among the different sites. Generally, the atmospheric deposition of soluble $\mathrm{Pb}, \mathrm{Cd}$, and $\mathrm{Cr}$ was higher in the southwest, central, south, and north China than in the northwest and northeast China, Inner Mongolia, and Qinghai-Tibet. As expected, the atmospheric heavy soluble metal deposition fluxes were significantly correlated with the number of vehicles $(P s<0.1)$. The wet deposition of soluble $\mathrm{Pb}$ and $\mathrm{Cr}$ was positively correlated with oil and coal consumption, unlike $\mathrm{Cd}$ deposition. Moreover, soluble $\mathrm{Pb}$ and $\mathrm{Cd}$ in atmospheric wet deposition were positively correlated with the contents of $\mathrm{Pb}$ and $\mathrm{Cd}$ in soil at different regions. In this study, atmospheric heavy metal deposition through rainfall in typical natural ecosystems in China is assessed at the national scale, alerting potential ecological hazards resulting from an increasing atmospheric heavy metal deposition and providing a basis for future studies.
\end{abstract}

() 2016 Elsevier Ltd. All rights reserved.

\section{Introduction}

Atmospheric wet deposition is commonly considered as the

\footnotetext{
* Corresponding author. Institute of Geographic Sciences and Natural Resources Research, Chinese Academy of Sciences, 11A, Datun Road, Chaoyang District, Beijing 100101, China.

** Corresponding author. Institute of Geographic Sciences and Natural Resources Research, Chinese Academy of Sciences, 11A, Datun Road, Chaoyang District, Beijing 100101, China.

E-mail addresses: qfwang@igsnrr.ac.cn (Q. Wang), henp@igsnrr.ac.cn (N. He).
}

most effective approach to remove various pollutants from the atmosphere and is one of the main sources of toxic heavy metal input to natural terrestrial ecosystems (Al-Khashman et al., 2013; Pan and Wang, 2015). In the past decades, anthropogenic activities have significantly altered airborne heavy metals through global population growth and industrialization (Bacardit and Camarero, 2009; Lei et al., 2011). Atmospheric heavy metals mainly originate from artificial sources, e.g., smelting, fossil fuel combustion, and waste incineration, with a relatively minor contribution from natural sources, e.g., soil dust and volcanic activity (Bacardit and Camarero, 2009; Cheng and Hu, 2010). Most atmospheric heavy metals 
eventually deposit on the surface through dry and wet deposition. Some heavy metals, such as lead $(\mathrm{Pb})$, cadmium $(\mathrm{Cd})$, chromium $(\mathrm{Cr})$, mercury $(\mathrm{Hg})$, and arsenic (As) are poisonous for plants, animals, and humans, by altering their metabolism, inhibiting growth, and decreasing the production (Das et al., 1997; Nagajyoti et al., 2010; Singh et al., 2013). Despite current international efforts to effectively decrease the increasing ratios of atmospheric pollution, most natural terrestrial ecosystems are still considered at risk because of the long-term high-intensity atmospheric heavy metal deposition and pollution (Shanker et al., 2005; Bacardit and Camarero, 2009; Luo et al., 2013; Bian et al., 2015).

Although some studies have investigated atmospheric heavy metal deposition rates at a local scale and for small regions (Azimi et al., 2005; Sakata et al., 2008; Sharma et al., 2008; Kara et al., 2014; Pan and Wang, 2015), no results have been reported at regional or national scales. Furthermore, the atmospheric deposition of heavy metals is expected to be higher in urban and industrial areas than in remote natural ecosystems owing to the limited critical radius of atmospheric transport and the reduced emissions from anthropogenic activities. Unfortunately, most observation sites in previous studies were located in urban and industrial areas, such that their results cannot be used to estimate the heavy metal deposition and evaluate the impacts of heavy metal deposition on natural ecosystems or remote areas (Golomb et al., 1997; Hu and Balasubramanian, 2003; Sakata et al., 2008; Kim et al., 2012). It is therefore important to better quantity the pollution status resultant from atmospheric heavy metals in natural ecosystems and delineate future environmental protection policies.

Soluble fractions of deposited heavy metals are an important part of wet deposition, accounting for $37-100 \%$ of the total forms (Cizmecioglu and Muezzinoglu, 2008), and it is also believed that a greater proportion of water-soluble metals likely originate from anthropogenic sources (Voutsa and Samara, 2002; Heal et al., 2005). Moreover, heavy metals are bioavailable and poisonous only in their soluble form. In this study, 31 field ecological stations from the Chinese Ecosystem Research Network (CERN) (Fu et al., 2010), which was initially established for monitoring N deposition (Zhu et al., 2015), were further selected to assess the atmospheric deposition of heavy metals $(\mathrm{Pb}, \mathrm{Cd}$, and $\mathrm{Cr}$ ) in their watersoluble form during rainfall (wet deposition) on a monthly basis by network monitoring in 2013 and 2014 (Fig. 1). To our knowledge, this study is the first attempt to evaluate the atmospheric heavy metals deposition flux through rainfall at the national scale considering Chinese terrestrial ecosystems. The main goals of this study were to 1) quantify the atmospheric heavy metal deposition through rainfall in Chinese natural ecosystems, 2) demonstrate the main factors influencing the wet deposition of atmospheric heavy metals, and 3) explore the relationship between atmospheric heavy metal deposition and soil metal content in China.

\section{Methods}

\subsection{Site description}

Thirty-one field ecological stations from the CERN were selected to monitor the atmospheric heavy metal deposition through rainfall (Table S1, Fig. 1). The stations were located in typical natural Chinese ecosystems, including forests, grasslands, deserts, lakes, marshes, and karst ecosystems, covering 20 Chinese provinces and eight ecological regions according to climate and vegetation (Fig. 1).

\subsection{Sampling and analysis}

According to the long-term monitoring guide from the CERN, rainwater (snow) was collected in plastic buckets installed $1.5 \mathrm{~m}$ above the ground at the onset of a rain (or snow) event. Samples were only collected over the duration of rainfall, and included rained out soluble and insoluble particulates. In detail, the samples were collected from 3 to 5 rainfall events per month in 2013-2014 by manual collection. After each rainfall event, the samples were stored in polyethylene plastic bottles under $-20^{\circ} \mathrm{C}$, and at the end of the month these subsamples were evenly mixed on an equalvolume-per-collection basis to obtain one mixed sample for each month. All plastic buckets and polyethylene plastic bottles were cleaned with distilled water three times and finally dried prior to use.

In general, there are three types of pretreatments for heavy metals in rainfall. The first one is to measure the heavy metal concentration after filtration, where the determined heavy metal concentration represents the water-soluble fraction (Cong et al., 2015). The second is to acidify the samples without filtration and then determine the heavy metal concentration to represent the concentration of acid-soluble fractions (Sakata and Asakura, 2009). The third is to use the acid digested method for the unfiltered precipitation and then determine the total heavy metal in rainfall (Cizmecioglu and Muezzinoglu, 2008; Pan and Wang, 2015). In this paper, we only measured water-soluble fractions of heavy metals in rainfall in the laboratory. These samples were filtered by gravity through a $0.45 \mu \mathrm{m}$ membrane filter to remove the particulates, and then the concentration of soluble $\mathrm{Pb}, \mathrm{Cd}$, and $\mathrm{Cr}$ were measured using an inductively coupled plasma optical emission spectrometer (ICP-OES) (Optima 5300DV, PerkinElmer, America). Duplicate blanks and standard reference materials (Chinese National Standards GB/T 23942-2009) were used to assure data quality. All blanks were analyzed in the same manner as field samples, and all procedures were applied for the blank samples. The $R^{2}$ of calibration curves for all heavy metals were $\geq 0.999$. The elements were not detected in blanks according to instrumental detected limits (1 ppb).

\subsection{Calculation and analysis}

The fluxes of atmospheric heavy soluble metal deposition through rainfall (or wet deposition) were calculated as:

$D=\sum_{i=1}^{\mathrm{n}} C_{\mathrm{i}} \times P_{\mathrm{i}}$

where $D\left(\mathrm{mg} \mathrm{m}^{-2}\right)$ is the annual deposition flux of a specific heavy metal (i.e., $\mathrm{Pb}, \mathrm{Cd}$, or $\mathrm{Cr}$ ), $C_{\mathrm{i}}$ is the monthly rainfall concentration of a specific heavy metal $\left(\mathrm{mg} \mathrm{L}^{-1}\right), P_{\mathrm{i}}$ is the monthly precipitation $(\mathrm{mm})$, and $n$ is the number of months.

Then, the atmospheric wet deposition fluxes of the heavy soluble metals for the eight regions were averaged for the observation sites in the specific regions. Similarly, we obtained the atmospheric heavy soluble metal deposition for the 20 provinces. Linear and curvilinear regressions were used to evaluate the relationships between the atmospheric heavy soluble metal deposition and the mean annual precipitation, number of vehicles, oil consumption, and coal consumption. The datasets for the number of vehicles, oil consumption, and coal consumption were obtained from the $\mathrm{Na}-$ tional Bureau of Statistics of China (Table S2). Data of heavy metal concentration in soil for different provinces of China were obtained from Chen et al. (2015), who obtained these values through a national soil heavy metal pollution survey. In their study, more than 38,000 topsoil samples were collected during April 2005 to December 2013 within the territory of the People's Republic of China (excluding the Hong Kong, Macao, and Taiwan). They used a standard method to analyze soil samples, and calculated metal 


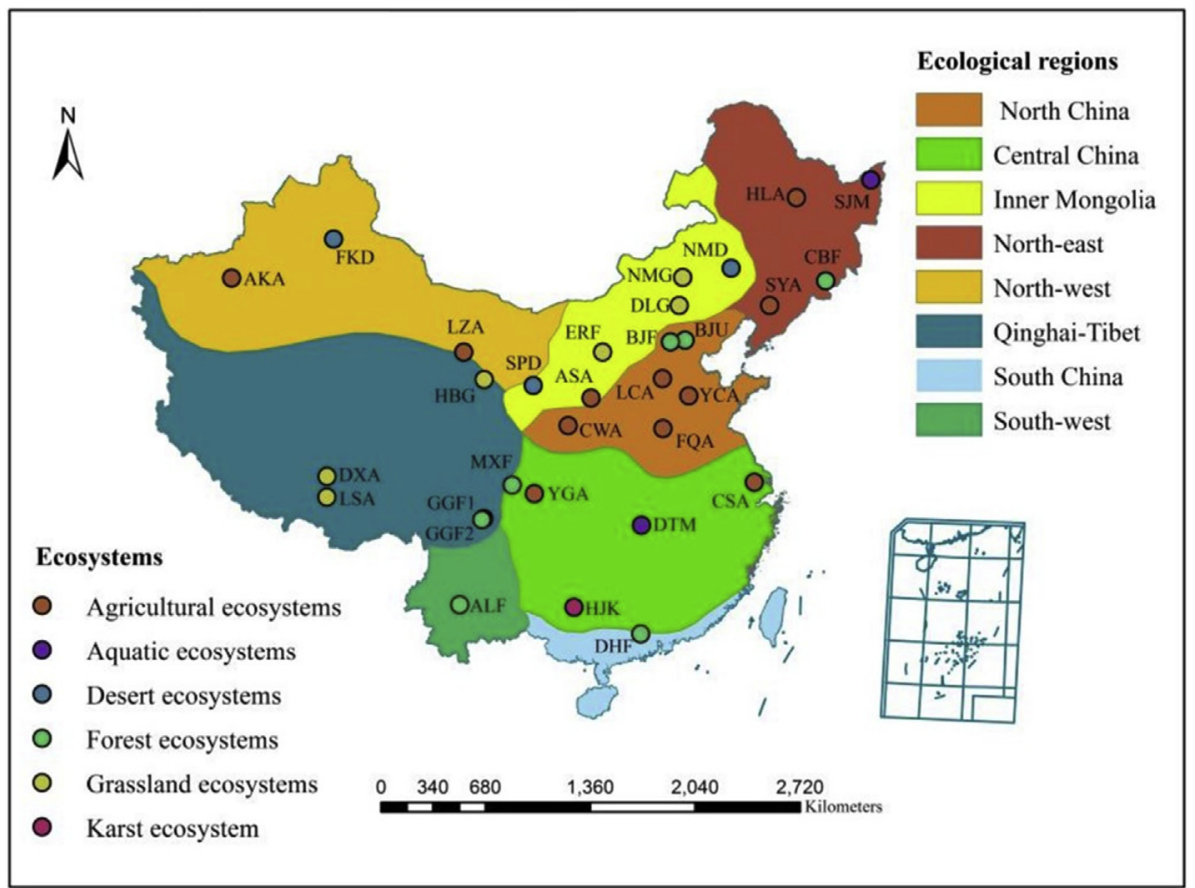

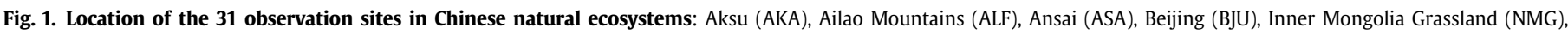

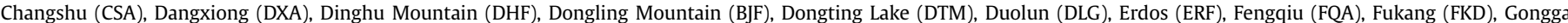

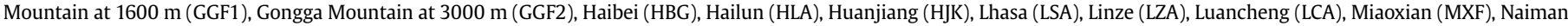

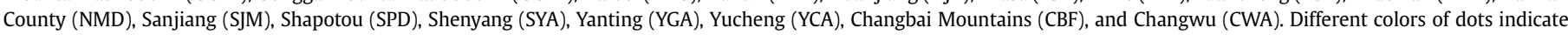
different ecosystem types.

contents in soil at the provincial scale. A significance level of $P<0.1$ was used for all tests. All analyses were conducted using the SPSS (Statistical Package for the Social Sciences) 13.0 program.

\section{Results}

3.1. Wet atmospheric heavy metal deposition at different sites and regions

The average atmospheric wet deposition of soluble $\mathrm{Pb}, \mathrm{Cd}$, and $\mathrm{Cr}$ in Chinese natural ecosystems was estimated to be $1.90 \pm 1.54$, $0.28 \pm 0.25$, and $0.96 \pm 0.48$, respectively. Meanwhile, the wet deposition was lowest in the northwest regions, with values of $0.22 \pm 0.23,0.06 \pm 0.05$, and $0.35 \pm 0.04 \mathrm{mg} \mathrm{m}^{-2} \mathrm{yr}^{-1}$ for soluble $\mathrm{Pb}$, $\mathrm{Cd}$, and $\mathrm{Cr}$, respectively, and much higher in the southwest, central, south, and north China (Fig. 2).

The fluxes of atmospheric wet deposition of heavy metals in 31 Chinese natural ecosystems were shown in Fig. 2. The atmospheric $\mathrm{Pb}, \mathrm{Cd}$, and $\mathrm{Cr}$ wet deposition ranged $0.06-5.80 \mathrm{mg} \mathrm{m}^{-2} \mathrm{yr}^{-1}$, $0.03-0.95 \mathrm{mg} \mathrm{m}^{-2} \mathrm{yr}^{-1}$, and $0.24-2.10 \mathrm{mg} \mathrm{m}^{-2} \mathrm{yr}^{-1}$, respectively. Specifically, soluble $\mathrm{Pb}, \mathrm{Cd}$, and $\mathrm{Cr}$ wet deposition all were highest in Ailao Mountains (ALF). $\mathrm{Pb}$ and $\mathrm{Cd}$ wet deposition were both lowest in Fukang (FKD), while $\mathrm{Cr}$ wet deposition was lowest in Shapotou (SPD). Moreover, the Pb deposition was the highest, and followed by $\mathrm{Cr}$ and $\mathrm{Cd}$.

\subsection{Factors influencing atmospheric wet heavy metal deposition}

The atmospheric heavy metal deposition was significantly correlated with the number of vehicles $(P<0.1$, Fig. 3). Moreover, atmospheric $\mathrm{Pb}$ and $\mathrm{Cr}$ deposition was also positively correlated with oil consumption $\left(R^{2}=0.48, P=0.001\right.$ for $\mathrm{Pb}, R^{2}=0.28$, $P=0.02$ for $\mathrm{Cr})$ and coal consumption $\left(R^{2}=0.39, P=0.003\right.$ for $\mathrm{Pb}$,

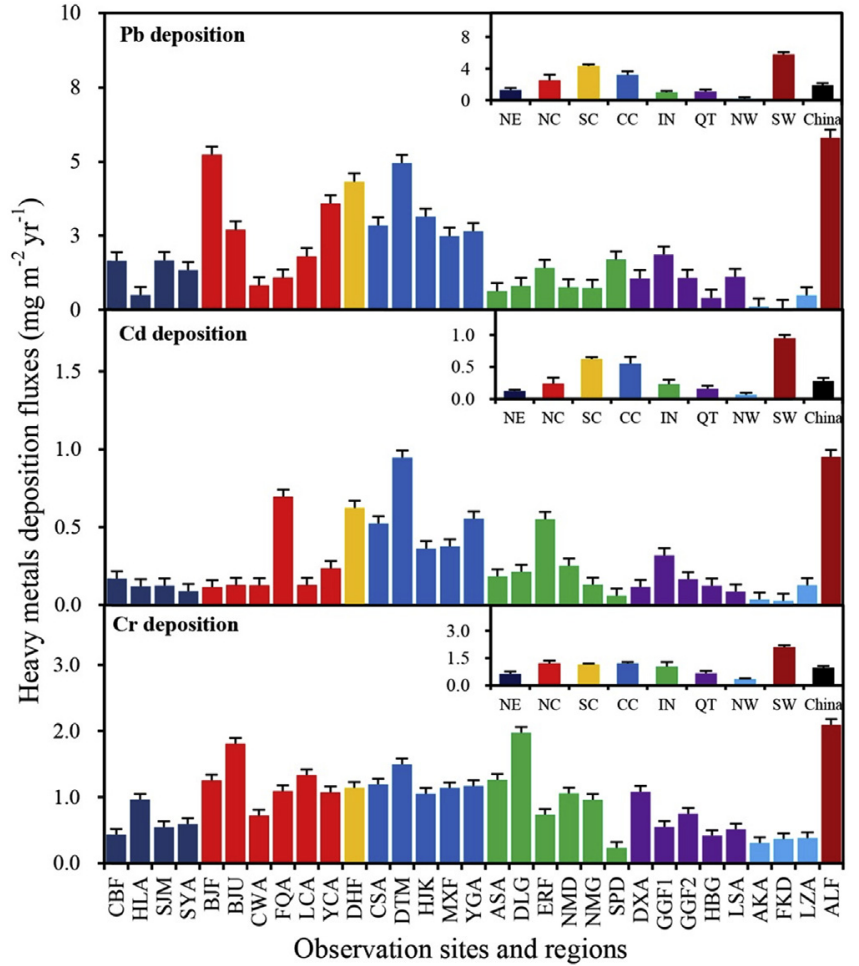

Fig. 2. Atmospheric heavy metal deposition through rainfall for different sites and regions. The eight regions represented are northwest China (NW), Inner Mongolia (IM), northeast China (NE), north China (NC), central China (CC), south China (SC), southwest China (SW), and Qinghai-Tibet (QT). Data with the same color located within the same regions. 


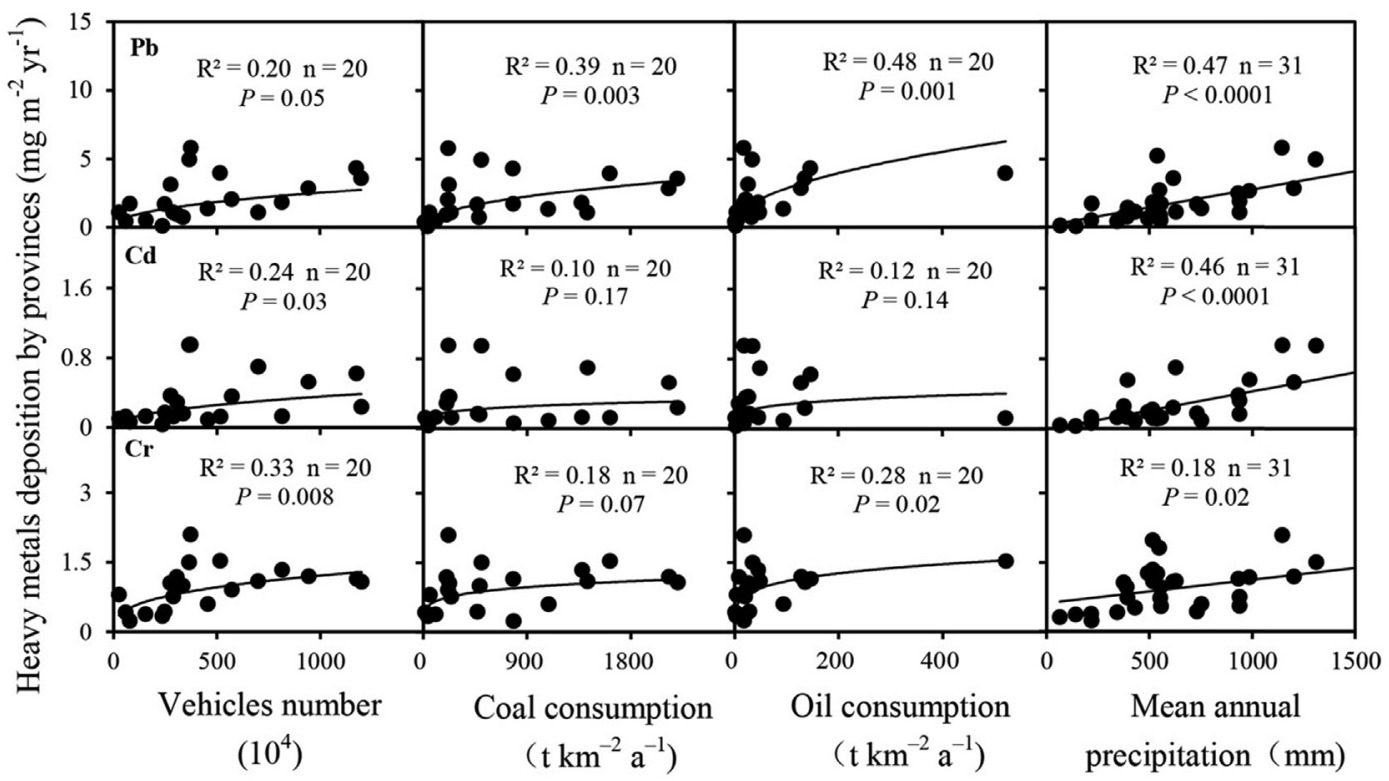

Fig. 3. Relationship between the atmospheric heavy metal deposition through rainfall and the number of vehicles, coal and oil consumption, and mean annual precipitation.

$R^{2}=0.18, P=0.07$ for $\mathrm{Cr}$ ). In contrast, the wet deposition of $\mathrm{Cd}$ was not significantly correlated with the oil $\left(R^{2}=0.12, P=0.14\right)$ and coal consumption $\left(R^{2}=0.10, P=0.17\right)$.

Meanwhile, the precipitation was an important driver for the spatial patterns of atmospheric deposition. The wet deposition of $\mathrm{Pb}\left(\mathrm{R}^{2}=0.47, P<0.0001\right), \mathrm{Cd}\left(\mathrm{R}^{2}=0.46, P<0.0001\right)$, and $\mathrm{Cr}$ $\left(\mathrm{R}^{2}=0.18, P=0.02\right)$ were closely correlated with the mean annual precipitation (MAP) (Fig. 3).

\subsection{Relationship between atmospheric heavy metal deposition and soil metal content}

The wet deposition of $\mathrm{Pb}$ was positively related with the soil $\mathrm{Pb}$
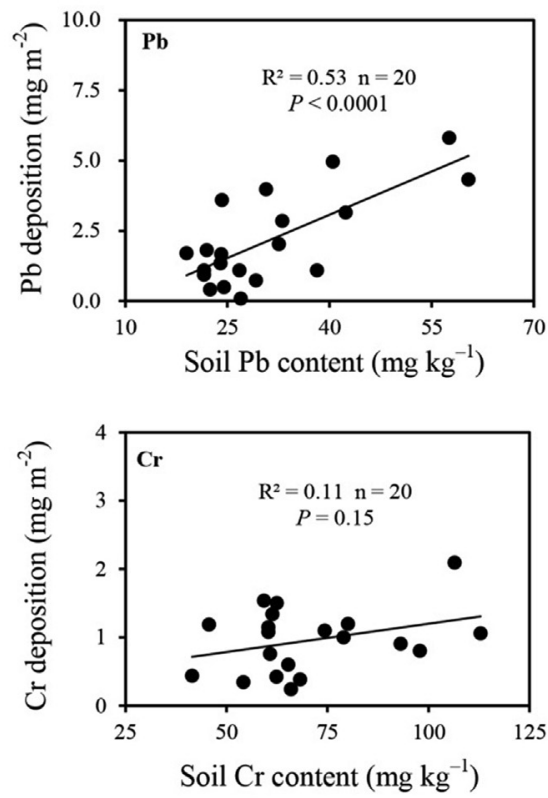

$\left(R^{2}=0.53, P<0.0001\right.$ for $\mathrm{Pb}$, Fig. 4$)$, while no apparent relationship between the $\mathrm{Cr}$ deposition and soil content was observed. The wet deposition of $\mathrm{Cd}$ was positively related with the soil $\mathrm{Cd}$ when the Guangxi province was not included in the fitting $\left(R^{2}=0.21, P=0.05\right.$ for $(d)$. However, when it was included, there was no significant relationship between them $\left(\mathrm{R}^{2}=0.04, P=0.41\right)$.

\section{Discussion}

\subsection{Atmospheric heavy metal deposition in Chinese terrestrial ecosystems}

The average atmospheric wet deposition of soluble $\mathrm{Pb}, \mathrm{Cd}$, and

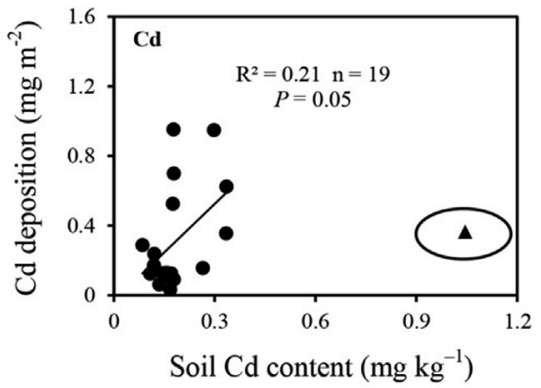

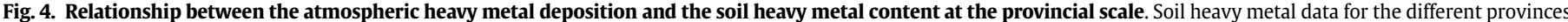

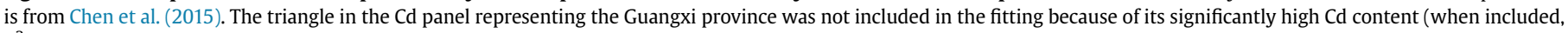
$\left.\mathrm{R}^{2}=0.04, \mathrm{P}=0.41\right)$. 
$\mathrm{Cr}$ in Chinese natural ecosystems was estimated to be $1.90 \pm 1.54$, $0.28 \pm 0.25$, and $0.96 \pm 0.48 \mathrm{mg} \mathrm{m}^{-2} \mathrm{yr}^{-1}$, respectively. Previous studies have reported heavy metals deposition only from scattered sites or regions and paid less attention on remote and rural sites; e.g., Pan and Wang (2015) reported that atmospheric wet deposition of $\mathrm{Pb}, \mathrm{Cd}$, and $\mathrm{Cr}$ were 4.0-10.0, 0.16-0.32, and $0.26-0.75 \mathrm{mg} \mathrm{m}^{-2} \mathrm{yr}^{-1}$ at 10 sites (only including 1 rural sites) in Northern China. The only rural sites in Xinglong (XL) also had relative high heavy metal deposition (Table 1) as the long-rang transport from upwind areas of Northern China, which was consistent with our observation in Dongling Mountain (BJF) in Northern China. Cong et al. (2015) reported that soluble Pb, Cd, and $\mathrm{Cr}$ in wet deposition in Qomolangma were 0.01, 0.0015 and $0.016 \mathrm{mg} \mathrm{m}^{-2} \mathrm{yr}^{-1}$, respectively, which was lower than our observation in Lhasa (LSA) and Dangxiong (DXA) in Tibet because of relative lack of disturbers in their research site. Other studies in different parts of the world also have recorded levels of atmospheric wet heavy metal deposition (Al-Momani, 2008; Kim et al., 2012; Connan et al., 2013; Cong et al., 2015; Pan and Wang, 2015), which indicated that the heavy metal deposition was comparable (Table 1). However, there are still no reports on heavy metal deposition at regional or national scales on natural ecosystems in China, which need to be emphasized.

The water soluble fraction of heavy metal deposition could roughly reflect the current status of heavy metal pollution in Chinese natural ecosystems; however, the deposition fluxes might be underestimated to some extent. Cizmecioglu and Muezzinoglu (2008) reported that the average percentages of water-soluble $\mathrm{Cr}$, $\mathrm{Cd}$, and $\mathrm{Pb}$ in rainfall samples were $80 \%, 87 \%$, and $93 \%$, respectively. Pan and Wang (2015) estimated that the concentrations of acidsoluble fraction for some elements, such as $\mathrm{Cd}$ and As, were comparable to that of the water-soluble fraction; however, for some other elements (such as $\mathrm{Cr}$ and $\mathrm{Pb}$ ), their concentrations of acidsoluble fraction were significantly higher than those of watersoluble fractions. $\mathrm{pH}$ is an important factor determining the ratio of dissolved and insoluble heavy metal fractions, although $\mathrm{pH}$ had different effects on the solubility of elements. The mean annual $\mathrm{pH}$ of rainfall samples in 31 field stations ranged between 5.2 and 8.3 with an average of 6.8 in Chinese terrestrial ecosystems (unpublished data). Therefore, measuring the water-soluble fraction of heavy metal without the consideration of acidification would underestimate the soluble fraction of heavy metal to some extent, particularly for elements such as $\mathrm{Cr}$, which has a low solubility under a neutral condition. However, if there are no other acidic materials to change the $\mathrm{pH}$ of rainfall samples, the water-soluble fraction would be the real value of heavy metals in rainfall, which are harmful to the natural ecosystems directly. However, insoluble particulates are also an important part of wet deposition, and require further evaluation.

\subsection{Human activity influence on wet atmospheric heavy metal deposition}

Human activities exert an apparent impact on the atmospheric heavy metal deposition through rainfall at both local and regional scales. We analyzed the variation among the different regions and the results showed that the wet deposition was lowest in the northwest regions, and much higher in the southwest, central, south, and north China, in agreement with their higher population density and economic level (Yue et al., 2005; Zhu et al., 2015).

$\mathrm{Pb}, \mathrm{Cd}$, and $\mathrm{Cr}$ in the atmosphere mainly derive from road traffic, fossil fuel combustion, and smelting (Sternbeck et al., 2002; Kara et al., 2014). The atmospheric heavy metal deposition was significantly correlated with the number of vehicles $(P<0.1$, Fig. 3$)$, suggesting a future increase in the heavy metal deposition with the increasing number of vehicles. Atmospheric soluble $\mathrm{Pb}$ and $\mathrm{Cr}$ deposition was also positively correlated with oil consumption and coal consumption. Nevertheless, the wet deposition of soluble Cd was not significantly correlated with the oil and coal consumption. Cong et al. (2015) found that atmospheric heavy metal deposition in the Qomolangma station was low because of its high elevation and apparent lack of polluters and disturbers. Recently, Pan and Wang (2015) pointed out that the atmospheric wet deposition of $\mathrm{Pb}$ was much higher in Xinglong (XL) in northern China (even higher than that in urban or industrial sites), reaching $8.4 \mathrm{mg} \mathrm{m}^{-2} \mathrm{yr}^{-1}$. Even though there were no local emission sources near remote research sites, the long-range transport of heavy metal pollutant from upwind areas and around metropolis might lead to the higher heavy metal deposition in those sites. Meanwhile, the precipitation was an important driver for the spatial patterns of atmospheric deposition. The wet deposition of soluble $\mathrm{Pb}, \mathrm{Cd}$, and $\mathrm{Cr}$ were closely correlated with the MAP (Fig. 3). It was clear that precipitation changes significantly affected wet heavy metal deposition, potentially leading to a higher deposition in the rainy season than in the dry season (Pan and Wang, 2015). Therefore, there were clear differences among the observation sites as the different anthropogenic disturbances, topographic and geomorphic conditions, and distance to important pollutant sources, which might partially explain the large variations in atmospheric heavy metal deposition observed among these sites.

\subsection{Relationship between atmospheric heavy metal deposition and soil metal content}

Heavy metal pollution from human activities influences and endangers the health and stability of natural ecosystems at different levels (e.g., atmosphere, water, soil, plants). Except for this study on atmospheric heavy metal deposition, previous studies have mainly focused on river (Muller et al., 2008), lake (Yin et al., 2011), and soil (Wang and Stuanes, 2003; Chen et al., 2015) pollution. Chen et al. (2015) analyzed a dataset from a national soil heavy metal pollution survey in China. The heavy metal contents in the soil were relatively higher in the southern Chinese provinces than in the north, which might be related with the higher geochemical background in the southwest and higher intensity of human activities in the southeast (Chen et al., 2015). In this study, the wet deposition of $\mathrm{Pb}$ and $\mathrm{Cd}$ was positively related with the soil $\mathrm{Pb}$ and Cd contents $\left(R^{2}=0.53, P<0.0001\right.$ for $\mathrm{Pb}, R^{2}=0.21, P=0.05$ for $\mathrm{Cd}$,

Table 1

Rates of atmospheric heavy metal deposition through rainfall from previous literature and the present study (in $\mathrm{mg} \mathrm{m}^{-2} \mathrm{yr}^{-1}$ ).

\begin{tabular}{|c|c|c|c|c|c|c|c|}
\hline Site & Time & Location & No. of sites & $\mathrm{Pb}$ & $\mathrm{Cd}$ & $\mathrm{Cr}$ & Reference \\
\hline Northern China & 2007-2010 & Urban/industrial/rural & 10 & $4.0-10.0$ & $0.16-0.32$ & $0.26-0.75$ & Pan and Wang, 2015 \\
\hline XL, Northern China & $2007-2010$ & Rural/remote & 1 & 8.4 & 0.19 & 0.29 & Pan and Wang, 2015 \\
\hline Chuncheon, Korea & $2006-2009$ & Rural/remote & 1 & 1.06 & 0.05 & - & Kim et al., 2012 \\
\hline Qomolangma, China & 2009-2010 & Rural/remote & 1 & 0.01 & 0.0015 & 0.016 & Cong et al., 2015 \\
\hline Northern Jordan & 1998-2000 & Rural/remote & 1 & 0.50 & 0.092 & - & Al-Momani, 2008 \\
\hline Marais Vernier, France & 2010-2012 & Rural/remote & 1 & 3.2 & 0.11 & - & Connan et al., 2013 \\
\hline China & $2013-2014$ & Rural/remote & 31 & $0.06-5.80$ & $0.03-0.95$ & $0.24-2.10$ & This study \\
\hline
\end{tabular}


Fig. 4), while no apparent relationship between the $\mathrm{Cr}$ deposition and soil content was observed. This similar spatial pattern between atmospheric heavy metal deposition and soil heavy metal contents indicates that heavy metals, particularly those from anthropogenic sources, can influence the different components of terrestrial ecosystems at the same spatial and temporal scale. Wet heavy metal deposition might reflect the pollution status of other terrestrial components, such as water and soil. Based on environmental monitoring data and random sampling, Wang and Stuanes (2003) reported that the heavy metal pollution in the air-water-soilplant system of Zhuzhou city was interrelated because of the same sources and transport channels of heavy metal pollution.

Chronic and increasing atmospheric heavy metal deposition may have potentially adverse effects on natural ecosystems and human welfare, since heavy metal pollution is invisible, long-term, and non-reversible (Cheng, 2003). Heavy metals may interfere with physiological and biochemical processes of plants such as their gaseous exchange, $\mathrm{CO}_{2}$ fixation, respiration, and nutrient absorption, and consequently the whole terrestrial ecosystem (Das et al., 1997; Nagajyoti et al., 2010; Singh et al., 2013). Furthermore, the accumulation of heavy metals in plants may result in their transfer through the food chain to different ecosystem levels, eventually transferring the toxicity and consequent diseases of geological and environmental origin to humans (Cheng, 2003; Jarup, 2003). Therefore, the implementation of effective measures would be of great value on Chinese natural ecosystems.

\section{Conclusions}

The atmospheric deposition of heavy metals through rainfall was observed for most natural Chinese ecosystems in China. The average atmospheric wet deposition of soluble $\mathrm{Pb}, \mathrm{Cd}$, and $\mathrm{Cr}$ in Chinese natural ecosystems were estimated to be $1.90 \pm 1.54$, $0.28 \pm 0.25$, and $0.96 \pm 0.48 \mathrm{mg} \mathrm{m}^{-2} \mathrm{yr}^{-1}$, respectively. The wet deposition of heavy metals in China showed an apparent spatial variability, being lowest in the northwest and higher in the southwest, central, south, and north China. The level of industrial development and energy consumption were significantly correlated with wet heavy metal deposition. Our study provides a rough estimate of atmospheric heavy metal deposition through rainfall in China, and highlighted an urgent demand for implementing some effective measures to protect natural ecosystems.

\section{Acknowledgements}

We are grateful to the ecological stations and all monitors from the Chinese Ecosystem Research Network (CERN) for sample collecting. This work was partially supported by the National Nature Science Foundation of China (31570471, 31290221, and 31470506), the Program for "Kezhen" Distinguished Talents in Institute of Geographic Sciences and Natural Resources Research, CAS (2013RC102), and Youth Innovation Promotion Association of CAS.

\section{Appendix A. Supplementary data}

Supplementary data related to this article can be found at http:// dx.doi.org/10.1016/j.chemosphere.2016.08.105.

\section{References}

Al-Khashman, O.A., Jaradat, A.Q., Salameh, E., 2013. Five-year monitoring study of chemical characteristics of wet atmospheric precipitation in the southern region of Jordan. Environ. Monit. Assess. 185, 5715-5727.

Al-Momani, I.F., 2008. Wet and dry deposition fluxes of inorganic chemical species at a rural site in Northern Jordan. Arch. Environ. Contam. Toxicol. 55, 558-565. Azimi, S., Rocher, V., Garnaud, S., Varrault, G., Thevenot, D.R., 2005. Decrease of atmospheric deposition of heavy metals in an urban area from 1994 to 2002 (Paris, France). Chemosphere 61, 645-651.

Bacardit, M., Camarero, L., 2009. Fluxes of Al, Fe, Ti, Mn, Pb, Cd, Zn, Ni, Cu, and As in monthly bulk deposition over the Pyrenees (SW Europe): the influence of meteorology on the atmospheric component of trace element cycles and its implications for high mountain lakes. J. Geophys Res.Biogeo. 114.

Bian, B., Zhou, L.J., Li, L., Lv, L., Fan, Y.M., 2015. Risk assessment of heavy metals in air, water, vegetables, grains, and related soils irrigated with biogas slurry in Taihu Basin, China. Environ. Sci. Pollut. Res. 22, 7794-7807.

Chen, H.Y., Teng, Y.G., Lu, S.J., Wang, Y.Y., Wang, J.S., 2015. Contamination features and health risk of soil heavy metals in China. Sci. Total Environ. 512, 143-153.

Cheng, H.F., Hu, Y.A., 2010. Lead (Pb) isotopic fingerprinting and its applications in lead pollution studies in China: a review. Environ. Pollut. 158, 1134-1146.

Cheng, S.P., 2003. Heavy metal pollution in China: origin, pattern and control. Environ. Sci. Pollut. R. 10, 192-198.

Cizmecioglu, S.C., Muezzinoglu, A., 2008. Solubility of deposited airborne heavy metals. Atmos. Res. 89, 396-404.

Cong, Z.Y., Kang, S.C., Zhang, Y.L., Gao, S.P., Wang, Z.Y., Liu, B., Wan, X., 2015. New insights into trace element wet deposition in the Himalayas: amounts, seasonal patterns, and implications. Environ. Sci. Pollut. R. 22, 2735-2744.

Connan, O., Maro, D., Hebert, D., Roupsard, P., Goujon, R., Letellier, B., Le Cavelier, S., 2013. Wet and dry deposition of particles associated metals (Cd, Pb, Zn, Ni, Hg) in a rural wetland site, Marais Vernier, France. Atmos, Environ, 67, 394-403.

Das, P., Samantaray, S., Rout, G.R., 1997. Studies on cadmium toxicity in plants: a review. Environ. Pollut. 98, 29-36.

Fu, B.J., Li, S.G., Yu, X.B., Yang, P., Yu, G.R., Feng, R.G., Zhuang, X.L., 2010. Chinese ecosystem research network: progress and perspectives. Ecol. Complex. 7, 225-233.

Golomb, D., Ryan, D., Eby, N., Underhill, J., Zemba, S., 1997. Atmospheric deposition of toxics onto Massachusetts Bay .1. Metals. Atmos. Environ. 31, 1349-1359.

Heal, M.R., Hibbs, L.R., Agius, R.M., Beverland, L.J, 2005. Total and water-soluble trace metal content of urban background PM10, PM2.5 and black smoke in Edinburgh, UK. Atmos. Environ. 39, 1417-1430.

Hu, G.P., Balasubramanian, R., 2003. Wet deposition of trace metals in Singapore. Water Air Soil Pollut. 144, 285-300.

Jarup, L., 2003. Hazards of heavy metal contamination. Br. Med. Bull. 68, 167-182.

Kara, M., Dumanoglu, Y., Altiok, H., Elbir, T., Odabasi, M., Bayram, A., 2014. Seasonal and spatial variations of atmospheric trace elemental deposition in the Aliaga industrial region, Turkey. Atmos. Res. 149, 204-216.

Kim, J.E., Han, Y.J., Kim, P.R., Holsen, T.M., 2012. Factors influencing atmospheric wet deposition of trace elements in rural Korea. Atmos. Res. 116, 185-194.

Lei, Y., Zhang, Q., He, K.B., Streets, D.G., 2011. Primary anthropogenic aerosol emission trends for China, 1990-2005. Atmos. Chem. Phys. 11, 931-954.

Luo, J.M., Yin, X.R., Ya, J., Wang, Y.J., Zang, S.Y., Zhou, X., 2013. Pb and Cd bioaccumulations in the habitat and preys of red-crowned cranes (Grus japonensis) in Zhalong wetland, northeastern China. Biol. Trace Elem. Res. 156, 134-143.

Muller, B., Berg, M., Yao, Z.P., Zhang, X.F., Wang, D., Pfluger, A., 2008. How polluted is the Yangtze River? Water quality downstream from the three Gorges Dam. Sci. Total Environ. 402, 232-247.

Nagajyoti, P.C., Lee, K.D., Sreekanth, T.V.M., 2010. Heavy metals, occurrence and toxicity for plants: a review. Environ. Chem. Lett. 8, 199-216.

Pan, Y.P., Wang, Y.S., 2015. Atmospheric wet and dry deposition of trace elements at 10 sites in Northern China. Atmos. Chem. Phys. 15, 951-972.

Sakata, M., Asakura, K., 2009. Factors contributing to seasonal variations in wet deposition fluxes of trace elements at sites along Japan Sea coast. Atmos. Environ. 43, 3867-3875.

Sakata, M., Tani, Y., Takagi, T., 2008. Wet and dry deposition fluxes of trace elements in Tokyo Bay. Atmos. Environ. 42, 5913-5922.

Shanker, A.K., Cervantes, C., Loza-Tavera, H., Avudainayagam, S., 2005. Chromium toxicity in plants. Environ. Int. 31, 739-753.

Sharma, R.K., Agrawal, M., Marshall, F.M., 2008. Atmospheric deposition of heavy metals (Cu, Zn, Cd and $\mathrm{Pb})$ in Varanasi City, India. Environ. Monit. Assess. 142, 269-278.

Singh, H.P., Mahajan, P., Kaur, S., Batish, D.R., Kohli, R.K., 2013. Chromium toxicity and tolerance in plants. Environ. Chem. Lett. 11, 229-254.

Sternbeck, J., Sjodin, A., Andreasson, K., 2002. Metal emissions from road traffic and the influence of resuspension - results from two tunnel studies. Atmos. Environ. 36, 4735-4744.

Voutsa, D., Samara, C., 2002. Labile and bioaccessible fractions of heavy metals in the airborne particulate matter from urban and industrial areas. Atmos. Environ. 36, 3583-3590.

Wang, H.Y., Stuanes, A.O., 2003. Heavy metal pollution in air-water-soil-plant system of Zhuzhou city, Hunan province, China. Water Air Soil Pollut. 147, 79-107.

Yin, H.B., Gao, Y.N., Fan, C.X., 2011. Distribution, sources and ecological risk assessment of heavy metals in surface sediments from Lake Taihu, China. Environ. Res. Lett. 6.

Yue, T.X., Wang, Y.A., Liu, J.Y., Chen, S.P., Qiu, D.S., Deng, X.Z., Liu, M.L., Tian, Y.Z., Su, B.P., 2005. Surface modelling of human population distribution in China. Ecol. Model. 181, 461-478.

Zhu, J., He, N., Wang, Q., Yuan, G., Wen, D., Yu, G., Jia, Y., 2015. The composition, spatial patterns, and influencing factors of atmospheric wet nitrogen deposition in Chinese terrestrial ecosystems. Sci. Total Environ. 511, 777-785. 